OPEN ACCESS

Edited by:

Matthew J. Potthoff,

University of lowa, USA

Reviewed by:

Martin Jastroch,

Helmholtz Centre Munich, USA

Christopher Morrison,

Pennington Biomedical Research

Center, USA

*Correspondence:

Francesco S. Celi,

Division of Endocrinology and

Metabolism, Department of Internal

Medicine, Virginia Commonwealth

University School of Medicine,

1101 East Marshall Street,

PO Box, Sanger Hall,

Room 7-007, Richmond,

VA 23298, USA

fsceli@vcu.edu

Specialty section:

This article was submitted

to Cellular Endocrinology,

a section of the journal

Frontiers in Endocrinology

Received: 08 July 2015 Accepted: 07 September 2015 Published: 25 September 2015

Citation:

Ni B, Farrar JS, Vaitkus JA and Celi FS (2015)

Metabolic effects of FGF-21: thermoregulation and beyond.

Front. Endocrinol. 6:148. doi: 10.3389/fendo.2015.00148

\section{Metabolic effects of FGF-21: thermoregulation and beyond}

\author{
Bin Ni, Jared S. Farrar, Janina A. Vaitkus and Francesco S. Celi* \\ Division of Endocrinology and Metabolism, Department of Internal Medicine, Virginia Commonwealth University School of \\ Medicine, Richmond, VA, USA
}

Fibroblast growth factor (FGF)-21, a member of the FGF family, is a novel hormone involved in the control of metabolism by modulating glucose homeostasis, insulin sensitivity, ketogenesis, and promoting adipose tissue "browning." Recent studies demonstrated that brown adipose tissue is not only a target for FGF-21, but is also a potentially important source of systemic FGF-21. These findings support the hypothesis that FGF-21 plays a physiologic role in thermogenesis and thermogenic recruitment of white adipose tissue by an autocrine-paracrine axis. This review examines the role of FGF-21 in thermogenesis from the perspective of cell-based, animal model, and human studies. We also present recent advances in the characterization of FGF-21's regulation of metabolism.

Keywords: FGF-21, fibroblast growth factor receptor, brown adipose tissue, metabolism, thermogenesis

\section{Introduction}

Fibroblast growth factors (FGFs) are a large family of polypeptide growth factors comprised of 22 different members, with molecular masses ranging from 17 to $34 \mathrm{kDa}$ sharing $13-71 \%$ amino acid identity. Among vertebrate species, FGFs are highly conserved in both gene structure and amino acid sequence (1). FGF-21 is a novel member of the FGF family and is predominantly expressed in the liver (2). FGF-21 activity depends on the membrane protein beta-klotho, a co-receptor with a very short cytoplasmic domain. FGF-21 binds beta-klotho with its C-terminus and directly interacts with FGF receptors (FGFRs) through its $\mathrm{N}$-terminus, resulting in FGFR activation (3). During the past decade, FGF-21 has been shown to be a novel regulator of metabolism and a potential therapeutic target for the treatment of obesity and diabetes (4).

Adipose tissue is one of the main targets of FGF-21 action, and mammals have at least two different types of fat: white and brown. White adipose tissue (WAT) is the primary site of energy storage and of release of hormones and cytokines that modulate whole-body metabolism and insulin resistance $(5,6)$. Brown adipose tissue (BAT) is not only an important body defense against hypothermia but also plays a role in diet-induced thermogenesis (7). This energy expenditure is in the form of thermogenesis, and is mediated by the expression of uncoupling protein 1 (UCP1). Hence, BAT can regulate whole-body metabolism and may alter insulin sensitivity and modify susceptibility to weight gain $(8,9)$.

\section{FGF-21-Induced Thermogenesis in Mice}

The first study of FGF-21's function on mouse core body temperature was performed in 2005 by Kharitonenkov and colleagues (4). Transgenic mice expressing human FGF-21 under the control of an $A P O E$ promoter and wild-type littermates were fed a high-fat/high-carbohydrate diet for 
15 weeks. FGF-21 transgenic mice were resistant to high-fat dietinduced obesity and their BAT was denser. At room temperature, FGF-21 transgenic mice had significantly lower body weight, fasting glucose levels and leptin levels, despite a much higher food intake compared to wild-type littermates. These data suggest that in a fed state, FGF-21 probably stimulates EE partially through increased BAT activation, which in turn results in an improved metabolism.

A study on the role of the peroxisome proliferator-activated receptor alpha (PPAR-alpha)/FGF-21 endocrine signaling pathway found that FGF-21 could reduce physical activity and promote torpor, a short-term hibernation-like state of regulated hypothermia that conserves energy (10). This was due to direct FGF-21 induction by PPAR-alpha in response to fasting, and pharmacologically by PPAR-alpha agonists. FGF-21, in turn, stimulated lipolysis in WAT and ketogenesis in the liver. In contrast to the previous study by Kharitonenkov and colleagues (4), the body temperatures of FGF-21 transgenic mice in this study were $1-2^{\circ} \mathrm{C}$ lower than their wild-type littermates. To examine whether core body temperature was also affected under conditions in which endogenous FGF-21 was increased, wild-type mice were infected with an FGF-21 expressing adenovirus. Administration of FGF21 resulted in reductions in both basal and fasting-induced body temperature. In addition to the reduced core body temperature, locomotor activity was also dramatically reduced in FGF-21 transgenic mice. These data suggest that during fasting states, FGF-21 may alter behavior to conserve energy.

Coskun et al. investigated the role of FGF-21 in obese mice (11). Systemic administration of FGF-21 for 2 weeks in dietinduced obese mice and $o b / o b$ mice lowered body weight by $20 \%$, predominantly via a reduction in adiposity. In this study, FGF-21-treated animals exhibited increased EE, fat utilization, and lipid excretion, reduced hepatosteatosis, and ameliorated hyperglycemia. In contrast to previous studies, no decrease in total caloric intake or an effect on physical activity levels were observed. After continuous infusion with FGF-21 (1 mg/kg/day) for 5 days, a small but significant elevation of core body temperature was observed $4 \mathrm{~h}$ after initiation of treatment, lasting for approximately $10 \mathrm{~h}$. FGF-21 also increased EE during both light and dark cycles, and depressed the respiratory quotient (RQ) in the dark cycles. The results of this study contrasts with an earlier report (10) where a reduction in body temperature was observed. It is important to note that in the former study, obese animals with ad libitum access to food were used and the body temperatures were measured in the fed state. Lower core body temperatures were only observed in lean, starved, and therefore energy-deprived FGF-21 transgenic mice and no such effects were reported in fed animals. Collectively, the data indicate a divergent effect of FGF-21 on core temperature, driven by the fed/fasting state.

Subsequently, Hondares and colleagues investigated the thermogenic effect of FGF-21 on newborn mice (12). This manuscript for the first time provided evidence suggesting that a metabolic regulator hormone, produced by the liver, could directly mediate activation of brown fat thermogenesis during the fetal-to-neonatal transition. The authors found low levels of FGF-21 in the plasma of fetal mice. After birth, however, plasma FGF-21 levels increased rapidly and remained high for 6 days before declining. Once weaning had completed, FGF21 levels were similar to adult mice. Similarly, Fgf21 mRNA levels in both fetal and newborn mouse liver were low. Soon after birth, $F g f 21$ was induced rapidly in the liver, with plasma FGF-21 levels reaching that of adults within $16 \mathrm{~h}$. To assess whether activation of PPAR-alpha could mediate the action of milk lipids on the Fgf21 gene, the authors studied PPAR-alpha null pups. Expression of Fgf21 at birth in the liver of PPARalpha null mice was lower than their wild-type littermates. Moreover, postnatal induction of the Fgf21 gene mediated by milk intake was completely suppressed in PPAR-alpha null pups. In wild-type pups starved after birth, injection of the PPAR-alpha agonist, pirinixic acid (Wy14,643) induced a significant increase in Fgf21 expression levels in the liver, whereas no such response was achieved in PPAR-alpha null pups. These results, consistent with previous observations (10), indicate that PPAR-alpha is necessary for $F g f 21$ induction in a fasting state.

Conversely, Hondares et al. (12) also found that FGF-21 could cause thermogenic activation of BAT in newborn mice and cultured brown adipocytes. The expression of thermogenic activation-related genes was increased in neonatal BAT after birth, in parallel with the rise in plasma FGF-21 levels. This study also treated neonate pups with a single dose of recombinant mouse FGF-21 $4 \mathrm{~h}$ after birth, without further suckling. A small, but statistically significant reduction of blood glucose in the absence of differences in free fatty acids or $\beta$-hydroxybutyrate levels was observed. FGF-21 significantly induced the expression of genes encoding proteins involved in mitochondrial oxidation and BAT thermogenic activation, such as $P g c-1 \alpha$, Ucp1, Dio2, Cyt c, Lipe, Glut1, and Glut4. Additionally, FGF-21 also increased the protein levels of peroxisome proliferatoractivated receptor $\gamma$, coactivator $1 \alpha$ (PGC- $1 \alpha)$, UCP 1 , and Cytochrome c. Moreover, PPAR-alpha null pups exhibited a reduced postnatal induction of thermogenic genes, which was rescued with FGF-21 treatment immediately after birth. Taken together, these results (12) confirm the role of PPAR-alpha in $F g f-21$ induction and FGF-21 activation of BAT thermogenesis in neonatal mice.

To assess whether FGF-21 may act directly on BAT, mouse brown adipocytes were differentiated in culture and were then exposed to FGF-21. At $5 \mathrm{nM}, \mathrm{FGF}-21$ significantly induced the expression of genes involved in thermogenic activation (Pgc-1 $\alpha$, Ucp 1, Glut4, Cyt c), while a higher concentration of FGF-21 (50 nM) did not further enhance these effects. Finally, mitochondrial function assays demonstrated that FGF-21 caused a significant increase in brown adipocyte oxygen consumption. FGF-21 treatment increased oligomycin-resistant uncoupled phosphorylation, and resulted in a significant induction (roughly threefold) of glucose oxidation in brown adipocytes. Additionally, these data indicated that FGF-21 specifically targets BAT thermogenic activation and that in neonates, this may contribute to neonatal activation of BAT thermogenesis in response to the start of milk intake. Collectively, these studies in mice demonstrate that FGF-21 is an important regulator of metabolism during fasting and fed states. 


\section{Direct Release of FGF-21 by Brown Adipose Tissue}

Although the liver is a well-known site for FGF-21 generation (2), Hondares et al. studied whether thermogenic activation in adult mice could directly induce FGF-21 expression and release in BAT (13). In this study, adult male mice were exposed to a $4^{\circ} \mathrm{C}$ housing environment for 6 or $24 \mathrm{~h}$. This cold exposure caused a remarkable increase (40-fold) in Fgf21 expression levels in BAT. Chronic acclimation to $4^{\circ} \mathrm{C}$ over 30 days also resulted in a significant induction of $F g f 21$ expression. In contrast, $F g f 21$ expression levels were not significantly increased in the livers of mice acutely exposed to cold and were even reduced in mice acclimated to cold during a 30-day exposure. In mice exposed to cold for $24 \mathrm{~h}$, a modest increase in Fgf21 mRNA was observed in WAT. Thus, whereas Fgf21 mRNA levels in BAT at thermoneutrality were lower than in the liver and WAT, after thermogenic activation, BAT showed the highest levels of Fgf21 mRNA expression. Plasma levels of FGF-21 in mice did not change after $6 \mathrm{~h}$, but increased after $24 \mathrm{~h}$ of cold exposure, and increased even further after a 30-day cold acclimation period. The authors also found that there were significant negative arteriovenous gradients in FGF-21 concentration across interscapular BAT from rats after short term ( $24 \mathrm{~h}$ ) cold exposure and long term (30 day) acclimation to cold exposure, demonstrating a significant FGF-21 output from BAT. Very recently, Keipert and colleagues showed that in UCP-1 knockout mice, cold exposure induces a dramatic increase in FGF-21 serum levels and FGF-21 expression in BAT compared to wild-type controls (14). This experimental model of ablation of non-shivering thermogenesis (NST) provided compelling evidence that FGF-21 acts in an autocrine-paracrine fashion on BAT, contributing to the adaptive thermogenic response and browning of WAT, ultimately expanding the NST capacity.

\section{Molecular Mechanisms of FGF-21-Induced Thermogenesis}

The mechanisms which mediate the induction of Fgf21 gene expression in response to cold were also investigated by Hondares et al. (13). Norepinephrine, a main mediator of cold-induced thermogenic activation of BAT, significantly induced Fgf21 expression in cultured, differentiated mouse brown adipocytes. The same response was observed in brown adipocytes treated with cyclic adenosine monophosphate (cAMP). The induction of Fgf21 gene expression by either norepinephrine or cAMP in brown adipocytes led to a significant increase in the release of FGF-21 into the cell culture medium. Treatment of brown adipocytes with propranolol, a $\beta$-adrenergic antagonist, successfully suppressed the effects of norepinephrine on Fgf21 gene expression, whereas prazosin, an $\alpha$-adrenergic inhibitor, had no effect. Furthermore, treatment with a protein kinase A (PKA) inhibitor (H89) or p38 mitogen-activated protein kinase (MAPK) inhibitor (SB202190) suppressed the induction of Fgf21 gene expression by norepinephrine. These results indicate that norepinephrine acts through $\beta$-adrenergic receptors to increase cAMP levels, causing
cAMP-mediated activation of PKA and p38 MAPK pathways and induction of $\mathrm{Fgf2} 1$ gene expression.

The authors also used HIB-1B cells [a brown adipocyte cell line derived from a transgenic mouse brown fat tumor (15)] to further investigate how Fgf21 gene transcription was regulated. HIB-1B cells were co-transfected with a luciferase reporter construct with a Fgf21 gene promoter and active form of PKA. By treating with dibutyryl cAMP, a significant increase in $F g f 21$ promoter activity was found. Furthermore, both active (MKK6-Glu) and inactive (MKK6-K82A) forms of the upstream inducer of p38 MAPK, MKK6, were tested for their role in Fgf21 promoter activity. Only MKK6-Glu could significantly induce Fgf21 promoter activity after transfection in the cell, which indicated that PKA-mediated activation of $F g f 21$ transcription is p38 MAPK dependent. Additionally, in a chromatin immunoprecipitation experiment, a very strong binding of ATF2 (cyclic AMP-dependent transcription factor) to the Fgf21 promoter was observed, suggesting that cAMP can promote this binding event in brown adipocytes. These data provide a link between sympathetic activation during cold stress and the release of FGF-21 from brown adipocytes. Finally, this study also demonstrates that ATF2 binding to the Fgf21 gene promoter is essential for cAMP-dependent induction of Fgf21 gene transcription. Further studies investigating the binding of ATF2 to the Fgf21 promoter may reveal novel regulators and the role of histone remodeling in Fgf21 induction.

\section{FGF-21 Function in Human Brown Adipose Tissue}

In 2013, our lab first discovered the effects of mild cold exposure on circulating FGF-21 levels in healthy humans and its relationship with cold-induced thermogenesis and lipolysis (16). Twelve healthy volunteers were included in a randomized, single-blind, crossover intervention study. All subjects were exposed to 24 and $19^{\circ} \mathrm{C}$ in a whole-room indirect calorimeter for $12 \mathrm{~h}$. EE, plasma FGF-21, non-esterified fatty acid (NEFA), and adipose tissue glycerol concentrations were measured. First, we found that plasma FGF-21 exhibited a two- to threefold diurnal variation at $24^{\circ} \mathrm{C}$, peaking at 0800 hours and progressively dropping to a nadir at 1700 hours, before rising at 1900 hours. We next compared in the same volunteers FGF-21 levels in blood samples obtained at $24^{\circ} \mathrm{C}$ and at $19^{\circ} \mathrm{C}$. The diurnal rhythm of plasma FGF-21 concentration was retained at $19^{\circ} \mathrm{C}$; however, the rise in FGF-21 levels in the late afternoon observed at $24^{\circ} \mathrm{C}$ was not. Plasma FGF-21 concentration was significantly higher at $19^{\circ} \mathrm{C}$ compared with $24^{\circ} \mathrm{C}$ at paired time points of cold exposure. Compared with $24^{\circ} \mathrm{C}$, at $19^{\circ} \mathrm{C}$ the FGF-21 area-under-the-curve (AUC) was significantly increased. Also, the change in adipose tissue microdialysate glycerol concentrations between 19 and $24^{\circ} \mathrm{C}$ correlated positively with the change in plasma FGF-21 levels, but not the change in serum NEFA AUC. Total energy expenditure (TEE, or EE) was significantly higher at $19^{\circ} \mathrm{C}$ compared with $24^{\circ} \mathrm{C}$, and the change in plasma FGF-21 concentration correlated positively with the change in EE. In a multivariate analysis, the change in plasma FGF-21 concentrations predicted the change in TEE. Collectively, our study demonstrated that mild cold exposure elevates circulating FGF-21 levels in humans. Augmented FGF-21 levels correlated positively with 
increments of adipose tissue microdialyzate glycerol and TEE during cold exposure. To our knowledge, this was the first study revealing potential regulatory links between FGF-21, lipolysis, and cold-induced thermogenesis in humans.

More recently, we explored cold exposure-induced FGF-21 secretion in humans and compared it with FNDC5 (also termed Irisin) (17). To elucidate whether BAT is a significant source of cold-augmented FGF-21 secretion, we profiled FGF-21 levels in five healthy men, stratified by BAT status, during $5 \mathrm{~h}$ of either a mildly cold non-shivering condition $\left(19^{\circ} \mathrm{C}\right)$ or thermoneutrality $\left(24^{\circ} \mathrm{C}\right)$. Consistent with our previous findings, diurnal reduction of FGF-21 was blunted at $19^{\circ} \mathrm{C}$. However, the blunting effect was markedly greater in BAT-positive subjects compared to BATnegative subjects, translating to a total FGF-21 output more than sixfold higher in BAT-positive individuals. Since the subjects were of similar age and body composition, and differed only by BAT status, these associative results support BAT as a source of FGF-21 during cold exposure in humans. Interestingly, the biorhythm of FGF-21 was virtually identical when subjects were exposed to warm temperature $\left(27^{\circ} \mathrm{C}\right)$, and we observed a trend between FGF-21 diurnal reduction and shivering intensity (17).

We next examined the bioenergetic profiles of FGF-21-treated primary human adipocytes in vitro, which were established from deep neck fat biopsies, a location known to be enriched with beige adipocytes (18). FGF-21 treatment increased general BAT and beige gene expression, without altering expression levels of classic brown fat lineage genes. UCP1 protein, which was absent in untreated adipocytes, became strongly expressed following FGF-21 treatment. During an adipocyte thermogenic function assay, FGF-21 significantly enhanced adipocyte basal oxygen consumption rate measured with an extracellular fluid bioanalyzer. Pharmacological interrogation of mitochondrial respiration revealed augmentation of both forms of respiratory uncoupling (oligomycin resistant and maximal) by FGF-21 treatment. Since the primary function of BAT is the generation of heat, we quantified the heat production from adipocytes directly by infrared thermography. FGF-21 increased heat production only after norepinephrine exposure. Thus, not only norepinephrine is required for FGF-21 induction and release in BAT (13), it is also required for FGF-21-induced thermogenesis in BAT. In contrast, FNDC5 treatment enhanced adipocyte heat production dose dependently, and was further increased by norepinephrine (17).

Most recently, serum FGF-21 levels were correlated with BAT activity in humans (19). A total of 59 lean and healthy subjects were included in two different cooling protocols: air-cooling $(20,21)$ and water-perfused suit $(22,23)$, followed by a $\left[{ }^{18} \mathrm{~F}\right] \mathrm{FDG}-\mathrm{PET} / \mathrm{CT}$ scan as a measure for BAT activity. In agreement with our previous study, serum FGF-21 levels were positively correlated with human cold-induced BAT activity. Interestingly, this was observed only in men, although BAT is more likely to be detected in females than in males (24). In contrast to our previous studies, the authors did not find an effect of acute cold exposure on plasma FGF-21 levels, but did observe an increase after a 10-day cold acclimation period, in parallel with upregulation of BAT activity. These results further support a role for FGF-21 as a cold-induced activator and product of BAT. Additionally, basal FGF-21 levels correlated positively with the change in core body temperature upon cold exposure for both males and females in both the water-cooling group and the aircooling group. This result suggests that in humans, FGF-21 may play a novel role in maintaining core body temperature in response to reduced ambient temperature.

\section{Metabolic Benefits of an FGF-21 Analog}

In a clinical setting, elevated serum FGF-21 levels have been observed in obese, glucose intolerant, and diabetic patients (25-27). FGF-21 levels are positively correlated with adiposity, plasma glucose, and insulin levels (indices of insulin resistance and triglyceride (TG) levels), and negatively correlated with high-density lipoprotein cholesterol (HDL-C) (28). So far, no data are available on direct administration of native FGF-21 to humans; however, a FGF-21 analog (LY2405319) has shown promise in obese human subjects with type 2 diabetes $(29,30)$. LY2405319 is a biopharmaceutical optimization of native FGF-21 with enhanced physical stability, and is able to maintain biological potency in vivo more successfully than the native molecule (31). During a clinical study, LY2405319 (3, 10, $20 \mathrm{mg} / \mathrm{kg} /$ day) was injected subcutaneously for 28 days. Compared with placebo, the 10 and $20 \mathrm{mg}$ groups showed reductions in lowdensity lipoprotein cholesterol (LDL-C) by 29.5 and $20.2 \%$, respectively. An additional significant decrease in mean fasting TG levels appeared as early as day 2 for all three dosing groups. The reduction in fasting TG levels was maintained for the entire treatment period and was significantly different from baseline and placebo at the 10 and $20 \mathrm{mg}$ dosage levels. Total cholesterol concentrations were also lowered in the $10(-19.2 \%)$ and $20 \mathrm{mg} / \mathrm{kg} /$ day $(-15.4 \%)$ groups. Additionally, an increase of 15-20\% in HDL-C occurred across all three dosage groups. Compared with baseline, both 10 and $20 \mathrm{mg}$ dosage groups had a significant decrease in body weight $(-1.75$ and $-1.49 \mathrm{~kg}$ ). There was a trend of lower glucose levels in all dosage groups, and fasting insulin levels were significantly reduced in the $20 \mathrm{mg}$ dose group when compared to baseline. In mice, FGF-21 administration lowered body weight and increased metabolic rate without suppressing food intake (11). In the human clinical study, neither caloric intake nor EE were measured. However, the significant increase in $\beta$-hydroxybutyrate in all LY2405319-treated groups suggests that TEE might have been increased, since $\beta$-hydroxybutyrate has a substantial thermic effect in humans, leading to an increase in EE (32). Thus, it would appear that despite elevated baseline FGF-21 levels ("FGF-21 resistance"), obese individuals with type 2 diabetes may still benefit from administration of an FGF-21 analog. Future studies are still needed to determine the potential metabolic benefits of interventions, which increase endogenous FGF-21 levels in this population.

\section{Metabolic Benefits of FGF-21 May Be "Browning" Independent}

Brown adipose tissue has been increasingly recognized as a natural target for the modulation of EE. This tissue is very different from a white fat depot, in that it requires the uptake of free fatty acids and glucose for activation and expends energy instead of storing it (33). Although the most important functions of BAT in small mammals are thermogenesis and maintenance of core body temperature, more recent evidence has shown that 
this tissue may represent an important target in humans for the treatment of obesity (34-36) and type 2 diabetes (37-39). Due to FGF-21's function as an important thermogenic regulator, its role in energy metabolism has also been widely investigated (4, $11,40,41)$. These in vivo studies used $o b / o b, d b / d b$, diet-induced obese, and FGF-21 transgenic mice models. FGF-21 transgenic mice had significantly lower body weight, fasting glucose levels, and hepatic fat deposition. They also retained more BAT, had subcutaneous adipocytes of smaller size, and exhibited improved glucose clearance and insulin sensitivity when compared to control littermates. Pharmacologic administration of FGF-21 dose dependently $(0.1-10 \mathrm{mg} / \mathrm{kg} /$ day $)$ reduced body weight and whole-body fat mass in diet-induced obese mice by increasing EE and physical activity levels. In diet-induced obese mice, FGF-21 also reduced blood glucose, insulin, and lipid levels, and reversed hepatic steatosis. Similarly, FGF-21 administration improved hepatic and peripheral insulin sensitivity in both lean and dietinduced obese mice, independent of a reduction in body weight and adiposity. Finally, it is worth noting that exogenous FGF-21 can promote reductions in fasting glucose levels, body weight, and circulating lipid levels in obese diabetic rhesus monkeys (42).

Recently, it has been debated whether the metabolic benefits of FGF-21 are "browning" and UCP1 dependent (43-45). These articles highlight a common pharmacological role for FGF-21 independent from BAT, since FGF-21 is effective in UCP1 null mice to reduce food intake for the promotion of weight loss. The majority of FGF-21-driven metabolic endpoints seem to not require UCP1 nor white adipocyte browning (brite or beige adipocytes); the browning of WAT by FGF-21 is dependent on temperature and diet, and UCP1 is only essential for helping FGF-21 regulate EE. These results are not surprising because FGF-21 acts through a cell-surface receptor complex composed of conventional FGFRs and beta-klotho $(3,46,47)$. It is worth noting that both beta-klotho and FGFR1 are expressed not only in adipose tissue, but also in the liver and pancreas (48-50). Betaklotho is also expressed in the suprachiasmatic nucleus (SCN) of the hypothalamus and the dorsal vagal complex (DVC) of the hindbrain in mice and this expression allows FGF-21 to regulate circadian behavior and metabolism at the level of the central nervous system (CNS) (51). Interestingly, the same study noted that the metabolic effects of FGF-21 overexpression to reduce blood glucose and insulin levels required beta-klotho expression in the SCN. This suggests that the CNS is pivotal in modulating the metabolic actions of FGF-21 in peripheral tissues, such as the liver and adipose tissue, and future studies are necessary to elucidate these pathways.

Skeletal muscle is also a target tissue for FGF-21 function (45, $52,53)$. Skeletal muscle is strongly dependent on oxidative phosphorylation for energy production, and at the same time, skeletal muscle insulin resistance in type 2 diabetes and obesity involves dysregulation of the oxidation of both carbohydrate and lipid fuels. A recent study showed that in skeletal muscle from subjects with mitochondrial disorders, there was an increase in FGF21 expression likely representing a compensatory mechanism (54). FGF21 was induced in the skeletal muscle tissue of patients with mitochondrial oxidative phosphorylation deficiency and compensated for the metabolic energy deficiency by mammalian target of rapamycin
(mTOR) activities, which serve as a master regulator of cell metabolism and energy homeostasis (55) via the PI3K-Akt pathway in skeletal muscle cells. mTOR can also increase the expression levels of $Y Y 1$ and $P G C-1 \alpha$, resulting in enhanced mitochondrial oxidative function. FGF-21-enhanced mitochondrial function was also demonstrated by significant increases in mitochondrial ATP synthesis, oxygen consumption rate, glycolytic capacity, activity of citrate synthase, and expression of key energy metabolism genes, such as Glut1, Cpt1a, Cpt2, Cycs, and Idh3a. All of these regulatory changes and recent insights into FGF-21 signaling in the brain contribute to the new role of FGF-21 in lipid and glucose metabolism, independent of thermogenesis or WAT "browning."

\section{Concluding Remarks and Future Perspectives}

Fibroblast growth factor-21 is a pleiotropic metabolic regulator which can reverse obesity and diabetes in different animal models and whose pharmacologic effects can be "browning" or UCP1independent. In humans, a FGF-21 analog administration results in important metabolic effects, but further studies are required to elucidate the exact mechanisms of FGF-21 action. By taking advantage of dense phenotyping techniques with quantitative functional imaging of BAT, we hope to investigate whether or not individuals with greater initial BAT abundance or induced beige fat will have differential metabolic benefits during treatment with FGF-21 or its analogs (Figure 1).

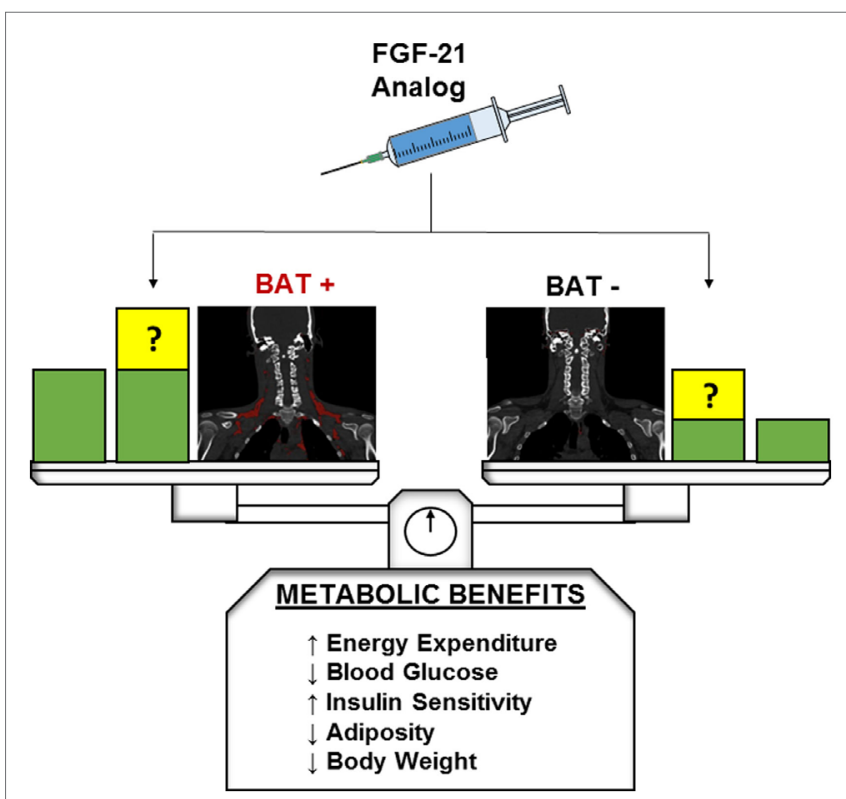

FIGURE 1 | Hypothetical metabolic benefits of FGF-21 in BAT-positive and BAT-negative individuals. Green blocks indicate theoretical baseline metabolic benefits without FGF-21 or analog administration. At baseline BAT-positive individuals are expected to exhibit greater beneficial metabolic profiles than their BAT-negative counterparts. Yellow blocks indicate potential changes to baseline metabolic benefits after FGF-21 or analog administration. The presence and magnitude of these changes in both BAT-positive and BAT-negative patients have yet to be elucidated and are a target of future research. 


\section{References}

1. Ornitz DM, Itoh N. Fibroblast growth factors. Genome Biol (2001) 2(3):REVIEWS3005. doi:10.1186/gb-2001-2-3-reviews3005

2. Nishimura T, Nakatake Y, Konishi M, Itoh N. Identification of a novel FGF, FGF-21, preferentially expressed in the liver. Biochim Biophys Acta (2000) 1492(1):203-6. doi:10.1016/S0167-4781(00)00067-1

3. Ding XS, Boney-Montoya J, Owen BM, Bookout AL, Coate KC, Mangelsdorf DJ, et al. beta Klotho is required for fibroblast growth factor 21 effects on growth and metabolism. Cell Metab (2012) 16(3):387-93. doi:10.1016/j. cmet.2012.08.002

4. Kharitonenkov A, Shiyanova TL, Koester A, Ford AM, Micanovic R, Galbreath EJ, et al. FGF-21 as a novel metabolic regulator. J Clin Invest (2005) 115(6):1627-35. doi:10.1172/Jci23606

5. Ronti T, Lupattelli G, Mannarino E. The endocrine function of adipose tissue: an update. Clin Endocrinol (Oxf) (2006) 64(4):355-65. doi:10.1111/j.1365-2265.2006.02474.x

6. Rosen ED, Spiegelman BM. Adipocytes as regulators of energy balance and glucose homeostasis. Nature (2006) 444(7121):847-53. doi:10.1038/ nature 05483

7. Cannon B, Nedergaard J. Brown adipose tissue: function and physiological significance. Physiol Rev (2004) 84(1):277-359. doi:10.1152/physrev.00015.2003

8. Lowell BB, Ssusulic V, Hamann A, Lawitts JA, Himmshagen J, Boyer BB, et al. Development of obesity in transgenic mice after genetic ablation of brown adipose-tissue. Nature (1993) 366(6457):740-2. doi:10.1038/366740a0

9. Celi FS, Le TN, Ni B. Physiology and relevance of human adaptive thermogenesis response. Trends Endocrinol Metab (2015) 26(5):238-47. doi:10.1016/ j.tem.2015.03.003

10. Inagaki T, Dutchak P, Zhao G, Ding X, Gautron L, Parameswara V, et al. Endocrine regulation of the fasting response by PPARalpha-mediated induction of fibroblast growth factor 21. Cell Metab (2007) 5(6):415-25. doi:10.1016/j.cmet.2007.05.003

11. Coskun T, Bina HA, Schneider MA, Dunbar JD, Hu CC, Chen Y, et al. Fibroblast growth factor 21 corrects obesity in mice. Endocrinology (2008) 149(12):6018-27. doi:10.1210/en.2008-0816

12. Hondares E, Rosell M, Gonzalez FJ, Giralt M, Iglesias R, Villarroya F. Hepatic FGF21 expression is induced at birth via PPARalpha in response to milk intake and contributes to thermogenic activation of neonatal brown fat. Cell Metab (2010) 11(3):206-12. doi:10.1016/j.cmet.2010.02.001

13. Hondares E, Iglesias R, Giralt A, Gonzalez FJ, Giralt M, Mampel T, et al. Thermogenic activation induces FGF21 expression and release in brown adipose tissue. J Biol Chem (2011) 286(15):12983-90. doi:10.1074/jbc. M110.215889

14. Keipert S, Kutschke M, Lamp D, Brachthauser L, Neff F, Meyer CW, et al. Genetic disruption of uncoupling protein 1 in mice renders brown adipose tissue a significant source of FGF21 secretion. Mol Metab (2015) 4(7):537-42. doi:10.1016/j.molmet.2015.04.006

15. Klaus S, Choy L, Champigny O, Cassard-Doulcier AM, Ross S, Spiegelman $\mathrm{B}$, et al. Characterization of the novel brown adipocyte cell line HIB $1 \mathrm{~B}$. Adrenergic pathways involved in regulation of uncoupling protein gene expression. J Cell Sci (1994) 107(Pt 1):313-9.

16. Lee P, Brychta RJ, Linderman J, Smith S, Chen KY, Celi FS. Mild cold exposure modulates fibroblast growth factor 21 (FGF21) diurnal rhythm in humans: relationship between FGF21 levels, lipolysis, and cold-induced thermogenesis. J Clin Endocrinol Metab (2013) 98(1):E98-102. doi:10.1210/jc.2012-3107

17. Lee P, Linderman JD, Smith S, Brychta RJ, Wang J, Idelson C, et al. Irisin and FGF21 are cold-induced endocrine activators of brown fat function in humans. Cell Metab (2014) 19(2):302-9. doi:10.1016/j.cmet.2013.12.017

18. Lee P, Werner CD, Kebebew E, Celi FS. Functional thermogenic beige adipogenesis is inducible in human neck fat. Int J Obes (Lond) (2014) 38(2):170-6. doi:10.1038/ijo.2013.82

19. Hanssen MJ, Broeders E, Samms RJ, Vosselman MJ, van der Lans AA, Cheng CC, et al. Serum FGF21 levels are associated with brown adipose tissue activity in humans. Sci Rep (2015) 5:10275. doi:10.1038/srep10275

20. Vosselman MJ, van der Lans AA, Brans B, Wierts R, van Baak MA, Schrauwen $\mathrm{P}$, et al. Systemic beta-adrenergic stimulation of thermogenesis is not accompanied by brown adipose tissue activity in humans. Diabetes (2012) 61(12):3106-13. doi:10.2337/db12-0288
21. Vosselman MJ, Brans B, van der Lans AA, Wierts R, van Baak MA, Mottaghy FM, et al. Brown adipose tissue activity after a high-calorie meal in humans. Am J Clin Nutr (2013) 98(1):57-64. doi:10.3945/ajcn.113.059022

22. van der Lans AA, Hoeks J, Brans B, Vijgen GH, Visser MG, Vosselman MJ, et al. Cold acclimation recruits human brown fat and increases nonshivering thermogenesis. J Clin Invest (2013) 123(8):3395-403. doi:10.1172/ JCI68993

23. Hanssen MJW, Wierts R, Hoeks J, Gemmink A, Brans B, Mottaghy FM, et al. Glucose uptake in human brown adipose tissue is impaired upon fasting-induced insulin resistance. Diabetologia (2015) 58(3):586-95. doi:10.1007/ s00125-014-3465-8

24. Nedergaard J, Bengtsson T, Cannon B. Three years with adult human brown adipose tissue. Ann N Y Acad Sci (2010) 1212:E20-36. doi:10.1111/j.1749-6632.2010.05905.x

25. Zhang X, Yeung DC, Karpisek M, Stejskal D, Zhou ZG, Liu F, et al. Serum FGF21 levels are increased in obesity and are independently associated with the metabolic syndrome in humans. Diabetes (2008) 57(5):1246-53. doi: $10.2337 / \mathrm{db} 07-1476$

26. Li L, Yang G, Ning H, Yang M, Liu H, Chen W. Plasma FGF-21 levels in type 2 diabetic patients with ketosis. Diabetes Res Clin Pract (2008) 82(2):209-13. doi:10.1016/j.diabres.2008.07.012

27. Lin Z, Gong Q, Wu C, Yu J, Lu T, Pan X, et al. Dynamic change of serum FGF21 levels in response to glucose challenge in human. J Clin Endocrinol Metab (2012) 97(7):E1224-8. doi:10.1210/jc.2012-1132

28. Semba RD, Sun K, Egan JM, Crasto C, Carlson OD, Ferrucci L. Relationship of serum fibroblast growth factor 21 with abnormal glucose metabolism and insulin resistance: the Baltimore Longitudinal Study of aging. JClin Endocrinol Metab (2012) 97(4):1375-82. doi:10.1210/jc.2011-2823

29. Gaich G, Chien JY, Fu H, Glass LC, Deeg MA, Holland WL, et al. The effects of LY2405319, an FGF21 analog, in obese human subjects with type 2 diabetes. Cell Metab (2013) 18(3):333-40. doi:10.1016/j.cmet.2013.08.005

30. Crunkhorn S. Metabolic disorders: FGF21 analogue shows promise in the clinic. Nat Rev Drug Discov (2013) 12(11):825-. doi:10.1038/Nrd4157

31. Kharitonenkov A, Beals JM, Micanovic R, Strifler BA, Rathnachalam R, Wroblewski VJ, et al. Rational design of a fibroblast growth factor 21-based clinical candidate, LY2405319. PLoS One (2013) 8(3):e58575. doi:10.1371/ journal.pone.0058575

32. Chiolero R, Mavrocordatos P, Burnier P, Cayeux MC, Schindler C, Jequier E, et al. Effects of infused sodium acetate, sodium lactate, and sodium beta-hydroxybutyrate on energy expenditure and substrate oxidation rates in lean humans. Am J Clin Nutr (1993) 58(5):608-13.

33. Celi FS. Brown adipose tissue - when it pays to be inefficient. N Engl J Med (2009) 360(15):1553-6. doi:10.1056/NEJMe0900466

34. Chechi K, Nedergaard J, Richard D. Brown adipose tissue as an anti-obesity tissue in humans. Obes Rev (2014) 15(2):92-106. doi:10.1111/Obr.12116

35. Sammons MF, Price DA. Modulation of adipose tissue thermogenesis as a method for increasing energy expenditure. Bioorg Med Chem Lett (2014) 24(2):425-9. doi:10.1016/j.bmcl.2013.12.016

36. Seale P, Lazar MA. Brown fat in humans: turning up the heat on obesity. Diabetes (2009) 58(7):1482-4. doi:10.2337/db09-0622

37. Schrauwen P, van Marken Lichtenbelt WD, Spiegelman BM. The future of brown adipose tissues in the treatment of type 2 diabetes. Diabetologia (2015) 58(8):1704-7. doi:10.1007/s00125-015-3611-y

38. Cypess AM, Kahn CR. Brown fat as a therapy for obesity and diabetes. Curr Opin Endocrinol Diabetes Obes (2010) 17(2):143-9. doi:10.1097/ MED.0b013e328337a81f

39. Chondronikola M, Volpi E, Borsheim E, Porter C, Annamalai P, Enerback S, et al. Brown adipose tissue improves whole-body glucose homeostasis and insulin sensitivity in humans. Diabetes (2014) 63(12):4089-99. doi:10.2337/ db14-0746

40. Xu J, Lloyd DJ, Hale C, Stanislaus S, Chen M, Sivits G, et al. Fibroblast growth factor 21 reverses hepatic steatosis, increases energy expenditure, and improves insulin sensitivity in diet-induced obese mice. Diabetes (2009) 58(1):250-9. doi:10.2337/db08-0392

41. Berglund ED, Li CY, Bina HA, Lynes SE, Michael MD, Shanafelt AB, et al. Fibroblast growth factor 21 controls glycemia via regulation of hepatic glucose flux and insulin sensitivity. Endocrinology (2009) 150(9):4084-93. doi:10.1210/ en.2009-0221 
42. Kharitonenkov A, Wroblewski VJ, Koester A, Chen YF, Clutinger CK, Tigno $\mathrm{XT}$, et al. The metabolic state of diabetic monkeys is regulated by fibroblast growth factor-21. Endocrinology (2007) 148(2):774-81. doi:10.1210/ En.2006-1168

43. Veniant MM, Sivits G, Helmering J, Komorowski R, Lee J, Fan W, et al. Pharmacologic effects of FGF21 are independent of the "browning" of white adipose tissue. Cell Metab (2015) 21(5):731-8. doi:10.1016/j.cmet.2015.04.019

44. Samms RJ, Smith DP, Cheng CC, Antonellis PP, Perfield JW II, Kharitonenkov A, et al. Discrete aspects of FGF21 in vivo pharmacology do not require UCP1. Cell Rep (2015) 11(7):991-9. doi:10.1016/j.celrep.2015.04.046

45. Camporez JPG, Jornayvaz FR, Petersen MC, Pesta D, Guigni BA, Serr J, et al. Cellular mechanisms by which FGF21 improves insulin sensitivity in male mice. Endocrinology (2013) 154(9):3099-109. doi:10.1210/En.2013-1191

46. Suzuki M, Uehara Y, Motomura-Matsuzaka K, Oki J, Koyama Y, Kimura M, et al. beta Klotho is required for fibroblast growth factor (FGF) 21 signaling through FGF receptor (FGFR) 1c and FGFR3c. Mol Endocrinol (2008) 22(4):1006-14. doi:10.1210/Me.2007-0313

47. Yie JM, Wang W, Deng LY, Tam LT, Stevens J, Chen MM, et al. Understanding the physical interactions in the FGF21/FGFR/beta-Klotho complex: structural requirements and implications in FGF21 signaling. Chem Biol Drug Des (2012) 79(4):398-410. doi:10.1111/j.1747-0285.2012.01325.x

48. Ito S, Kinoshita S, Shiraishi N, Nakagawa S, Sekine S, Fujimori T, et al. Molecular cloning and expression analyses of mouse betaklotho, which encodes a novel Klotho family protein. Mech Dev (2000) 98(1-2):115-9. doi:10.1016/S0925-4773(00)00439-1

49. Hughes SE. Localisation and differential expression of the fibroblast growth factor receptor (FGFR) multigene family in normal and atherosclerotic human arteries. Cardiovasc Res (1996) 32(3):557-69. doi:10.1016/ S0008-6363(96)00102-2
50. Hughes SE. Differential expression of the fibroblast growth factor receptor (FGFR) multigene family in normal human adult tissues. J Histochem Cytochem (1997) 45(7):1005-19. doi:10.1177/002215549704500710

51. Bookout AL, de Groot MH, Owen BM, Lee S, Gautron L, Lawrence HL, et al. FGF21 regulates metabolism and circadian behavior by acting on the nervous system. Nat Med (2013) 19(9):1147-52. doi:10.1038/nm.3249

52. Hojman P, Pedersen M, Nielsen AR, Krogh-Madsen R, Yfanti C, Akerstrom $\mathrm{T}$, et al. Fibroblast growth factor-21 is induced in human skeletal muscles by hyperinsulinemia. Diabetes (2009) 58(12):2797-801. doi:10.2337/Db09-0713

53. Kim KH, Kim SH, Min YK, Yang HM, Lee JB, Lee MS. Acute exercise induces FGF21 expression in mice and in healthy humans. PLoS One (2013) 8(5):e63517. doi:10.1371/journal.pone.0063517

54. Ji K, Zheng J, Lv J, Xu J, Ji X, Luo YB, et al. Skeletal muscle increases FGF21 expression in mitochondrial disorders to compensate for energy metabolic insufficiency by activating the mTOR-YY1-PGClalpha pathway. Free Radic Biol Med (2015) 84:161-70. doi:10.1016/j.freeradbiomed.2015.03.020

55. Laplante M, Sabatini DM. mTOR signaling at a glance. J Cell Sci (2009) 122(20):3589-94. doi:10.1242/Jcs.051011

Conflict of Interest Statement: The authors declare that the research was conducted in the absence of any commercial or financial relationships that could be construed as a potential conflict of interest.

Copyright (C) 2015 Ni, Farrar, Vaitkus and Celi. This is an open-access article distributed under the terms of the Creative Commons Attribution License (CC BY). The use, distribution or reproduction in other forums is permitted, provided the original author(s) or licensor are credited and that the original publication in this journal is cited, in accordance with accepted academic practice. No use, distribution or reproduction is permitted which does not comply with these terms. 